Hanneke Heinsman, Annebel H.B. de Hoogh, Paul L. Koopman, Jaap J. van Muijen*

\title{
Competency Management: Balancing Between Commitment and Control ${ }^{* *}$
}

This study investigated the relationships between commitment and control approaches and the use of competency management by adopting the theory of planned behavior. Questionnaires were filled out by 43 human resource experts working in different organizations. We expected components of the theory of planned behavior to mediate the relationship between commitment and control approaches and the use of competency management (behavior). Regression analysis showed that perceived behavioral control mediated the relation between commitment approach and behavior. Furthermore, the data revealed that attitude towards competency management was more positive and perceived behavioral control was higher when competency management was implemented with a commitment instead of a control approach. Subjective norm was strongly related to behavior. Based on the results, for competency management to be frequently used, we argue for increased behavioral control, and for an organizational climate in which competency management is widely accepted.

\section{Key words: Competency Management, Commitment, Control, Theory of Planned Behavior}

* Hanneke Heinsman, Annebel H.B. de Hoogh, and Paul L. Koopman, Department of Work and Organizational Psychology, Vrije Universiteit Amsterdam, The Netherlands. Jaap J. van Muijen, Institute for Leadership and Personal Development, Nyenrode Business Universiteit Breukelen/Jonathan Warner Amsterdam, The Netherlands.

Correspondence should be addressed to Hanneke Heinsman, Department of Work and Organizational Psychology, Vrije Universiteit Amsterdam, Van der Boechorststraat 1, 1081 BT Amsterdam, The Netherlands, e-mail: h.heinsman@psy.vu.nl.

** This study was supported by consultancy firm LTP as well as by the Dutch Society of Personnel Management and Organizational Development (NVP).

We thank Arjan Eleveld and Frank van Luijk for their useful comments on an earlier version of this article.

Article received: April 25, 2006

Revised version accepted after double blind review: July 3, 2006. 


\section{Introduction}

Competency management is an important human resource tool that is often used within organizations to guide human resource practices such as selection, assessment, career management, employee development, and performance appraisal. Competency management, if well embedded and integrated in the larger human resource system, can bring about a lot of advantages for the organization (e.g. Becker/Huselid 1999; Heinsman et al. 2005). However, implementing competency management is complicated. It requires internally consistent human resource policies and congruence with organizational characteristics, such as strategy and structure (Wright/McMahan 1992). Furthermore, an incorrect approach towards competency management may result in negative attitudes towards competency management, which in turn results in resistance and limited use of competency management. This raises the question how to change the attitude towards competency management and how to persuade employees to use competency management as a human resource tool.

In the present study we focus on two different approaches to competency management, namely commitment and control. Commitment and control represent two distinct approaches to shaping employee attitudes and behavior at work. Researchers have demonstrated a growing interest in the effects of human resource practices on employee attitude and behavior (e.g., Guest 1999). However, no study we know of has examined the effects of the commitment and control approaches to competency management on employee attitude towards and on the use of competency management (behavior). The aim of the current study is to fill this gap. To examine the effects of the commitment and control approaches on employee attitude and behavior we use several components of the theory of planned behavior (Ajzen, 1985 1991). This theory has proved its value in predicting a wide range of behaviors. However, it has never been used to study attitudes and behavior with respect to competency management.

\section{Competency Management; Commitment and Control}

During the past decades competency management has become a popular phenomenon in human resource management. Several years ago, Shippmann et al. (2000) noted that between $75 \%$ and $80 \%$ of surveyed companies had adopted some form of competencyrelated application. We expect this percentage to have grown in the past years. The modern competency movement dates from the late 1960s and early 1970s. Due to the rise of the Human Relations movement the focus on mass production and standardization of work processes was replaced by a focus on employee development. Technological change, globalized competition, and an ongoing interest in development fuelled the rise of competency management even more and caused an increase in the use of competency systems and competency models (Paulsson et al. 2005; Sugarman 2001).

In the Netherlands the interest in competencies has developed after the publication of Prahalad and Hamel (1990) on 'core competencies' of organizations. At that time, the Dutch economy slowly changed into a knowledge economy and employee development became increasingly important. The tight labor market made retaining and committing employees essential and competency management appeared to be a useful human resource tool for general managers. The commitment approach became 
more and more salient. This commitment approach (Walton, 1985) is characterized by viewing workers as means rather than objects and by winning hearts and minds (Guest 1999). Jobs are defined broadly, hierarchy is minimized, and control and coordination depend on shared goals rather than on formal positions. Motivating employees via personal development is central to the commitment approach (Bach 2000). For example, competency management became an important tool for career management. On the one hand career management, using competency management, focused on the development of individual competencies. On the other hand, competency management as a tool for career management made the link between developing individual and developing organizational competencies more salient.

Since 2001, due to the economic downfall, competency management is increasingly used for selection purposes and for performance appraisal in order to reduce labor costs, to improve performance standards and, in the end, to improve organizational effectiveness. Thus, managers use competency management as a tool for controlling the workforce. The control approach, as opposed to the commitment approach, is characterized by the wish to establish order, to exercise control, and to reduce labor costs (Walton, 1985). According to Koopman (1991) there is no doubt that the steering wheel is in hands of management. Employees are merely motivated by extrinsic rewards, which are dependent on measurable output criteria. Apparently, during the years there has been a shift from a commitment to a control approach to competency management.

The commitment and control approaches to human resource management have been an important topic in human resource literature (e.g., Boselie et al. 2004; Huselid 1995; Truss et al. 1997). Researchers have been focusing primarily on the relation between human resource management and performance (e.g., Boselie et al. 2001; Gelade/Ivery 2003; Huselid 1995). Previous theoretical as well as empirical studies have shown that the commitment approach has more positive effects on outcomes such as organizational performance and turnover than the control approach (e.g., Arthur 1994; Boselie et al. 2004). Recently, interest in the effects of human resource management approach on employee attitude and behavior is growing. Storey (1989), for example, suggested we need to study the impact of employment practices upon the recipients of messages and initiatives more systematically. Arthur (1994) studied the effects of human resource approaches (commitment and control) on manufacturing performance and turnover and concluded that there is an increasing need to demonstrate the different effects of commitment and control on employee attitudes and behavior.

Guest (1999) made a first attempt to actually study the workers' view on human resource management. Based on the results of an annual survey of employment relations, he suggested that the impact of human resource practices on employee's performance depends on their perception and evaluation of these practices. Thus, perceptions and attitude may mediate the relationship between human resource practices and (performance-related) behavior. However, Guest provides us with no insights in the effects of commitment and control approaches on employee attitude and behavior. Exploring these effects explicitly will undoubtedly lead to more insight in how to maximize the benefits of human research practices, such as competency management. 
The present study responds to the calls of Storey (1989) and Arthur (1994), and elaborates on the research done by Guest (1999). We examine the effects of the commitment and control approaches on employee attitude and behavior towards competency management. In line with Arthur (1994) and Boselie et al. (2004) we believe that the commitment approach leads to more positive "outcomes" than the control approach. Thus, in line with Guest (1999) we expect the commitment approach to have a more positive effect on variables such as attitude towards competency management than the control approach. Furthermore, we expect that the impact of the commitment and control approach on behavior, defined in terms of the use of competency management, is indirect rather than direct. More specific, following Guest (1999), we expect several variables, such as employee attitude, to mediate the relationship between the commitment and control approaches and the use of competency management. In studying the effects of the commitment and control approaches on attitude and behavior we use components of the theory of planned behavior (Ajzen, 1985 1991), which is described below.

Participants in this study are human resource experts. Competency management is salient in this group because they are confronted with the use of competency management in their daily work routines. In addition, they need to stimulate the use of competency management within the organization. It is, therefore, important to study the effects of the commitment and control approaches to competency management on the attitude and behavior of human resource experts. As we pointed out earlier, no study we know of has examined these effects, and with the present study we try to fill this gap.

\section{Theory of Planned Behavior}

The theory of planned behavior as proposed by Ajzen (1985 1991) is the successor of the theory of reasoned action (Fishbein/Ajzen, 1975). According to the theory of reasoned action, human behavior is predicted by the intentions people have to perform (or not perform) certain behaviors. These intentions are determined by attitudes towards that behavior as well as by the perceived social pressure (subjective norm) to perform that behavior. As mentioned before, the theory of planned behavior is an extension of the theory of reasoned action. According to the theory of planned behavior, perceived behavioral control, or the perceived ease or difficulty to perform a certain behavior, serves as a third determinant of human behavior. The relative importance of the determinants in the prediction of intention and behaviors varies across situations (Ajzen/Fishbein, 1980).

The theory of planned behavior has often been used to study the determinants of human behavior. It describes attitudes, subjective norms and perceived behavioral control as determinants of human behavior. Attitude to a certain behavior refers to the individual's global positive or negative evaluation of performing that behavior. In general, the more positive towards a certain behavior, the more likely it is an individual will perform that behavior. Thus, in the present context, the more positive one's feelings towards competency management, the more likely it is an employee will use competency management in daily work. Subjective norm refers to the individual's perceptions of general social pressure to perform a certain behavior. That is, the more social pressure the individual perceives from significant others to perform a certain 
behavior, the more likely it is that an individual will perform that behavior. Thus, in the present context, the higher the pressure of one's colleagues to use competency management, the more likely it is that the employee will use competency management in daily work. The determinant of perceived behavioral control refers to the perceived ease or difficulty of performing a certain behavior. In general, the more behavioral control an individual perceives in performing a certain behavior, the more likely it is an individual will perceive control over that behavior. Thus, in the present context, the more an employee beliefs he/she has the necessary skills and knowledge to use competency management the more likely it is the employee will use competency management in daily work.

In sum, applied to predicting the use of competency management, the theory of planned behavior states that the extent to which an employee has a positive or negative evaluation of competency management (attitude), the perception of social pressure to use competency management at work (subjective norm), and the employee's confidence in his/her ability to use competency management (perceived behavioral control) will predict the actual use of competency management.

As stated, researchers have been focusing primarily on the relation between the commitment and control approach and several outcome variables. In line with Arthur (1994), Guest (1999), and Storey (1989), we subscribe the need for research on employee attitude and behavior. Based on previous theoretical as well as empirical research it may be concluded that the commitment approach, characterized by winning hearts and minds and by motivating employees, has more positive effects on outcomes such as turnover and performance (e.g., Boselie et al. 2001; Gelade/Ivery 2003). In line, we expect the commitment approach to have more positive effects on attitude, subjective norm, and perceived behavioral control than the control approach. We, therefore, hypothesize:

Hypothesis 1: The commitment approach to competency management is more positively related to (a) attitude, (b) subjective norm, and (c) perceived behavioral control than the control approach to competency management.

The theory of planned behavior variables have proven to be valuable in predicting a wide range of behaviors, such as blood donation, driving violations, and job search behavior (Giles/Cairns 1995; Parker et al. 1992; Van Hooft et al. 2004). Although applicable in work related settings (Caska 1998; Van der Zee et al. 2002; Van Hooft 2004), no study we know of has used the theory of planned behavior to predict the use of competency management. Therefore, in the present study, we focus on the determinants of behavior and their effects on the use of competency management by human resource experts. In sum, we expect the following:

Hypothesis 2: (a) Attitude, (b) subjective norm, and (c) perceived behavioral control are positively related to behavior (the use of competency management).

Based on the theory of planned behavior, stating that attitude, subjective norm, and perceived behavioral control mediate the relationship between intention and actual behavior, we expect attitude, subjective norm, and perceived behavioral control to 
mediate the relationship between the commitment and the control approach and behavior, or more specifically the use of competency management. We therefore hypothesize:

Hypothesis 3: (a) Attitude, (b) subjective norm, and (c) perceived behavioral control mediate the relation between commitment and behavior (the use of competency management).

Hypothesis 4: (a) Attitude, (b) subjective norm, and (c) perceived behavioral control mediate the relation between control and behavior (the use of competency management).

These hypotheses lead to the research model as presented in Figure 1.

Figure 1: Overview of the research model

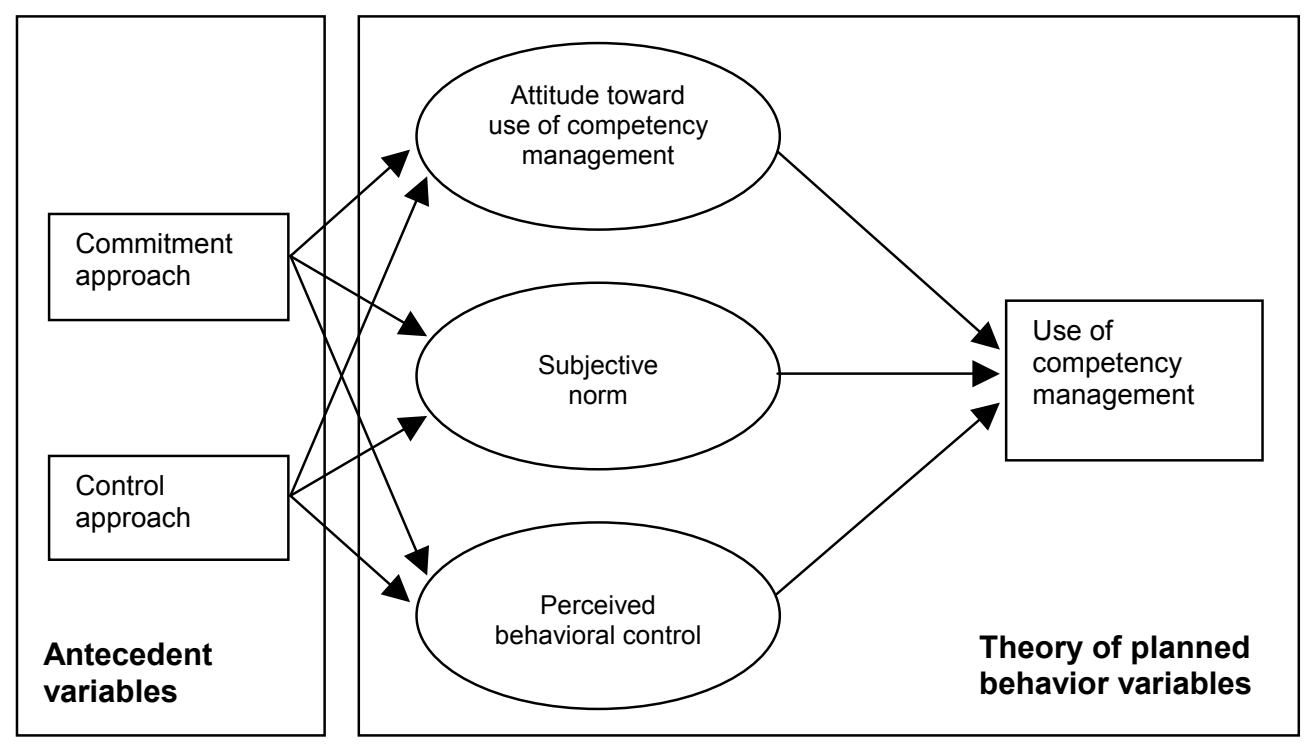

\section{Method}

\section{Respondents and Procedure}

Data for this study were collected with a survey instrument send to 2052 members (further called respondents) of the Dutch Society of Personnel Management and Organizational Development (NVP). The respondents were members of the division called Management Development and Human Resource Development and they were all working as human resource experts in different organizations. They received the questionnaire via email and were asked to fill out the questionnaire online. The data were collected over a six and a half week period in which members received two reminders by email. In order to generate a higher response rate, two books about HRM were disposed by lottery and respondents were invited to attend a meeting in which results would be presented by the researchers.

We received a total of 43 valid questionnaires, which resulted in a $2 \%$ response rate. This percentage is, in all likelihood, a very conservative estimate because non- 
respondents included many people who, for a variety of reasons, could not respond. These reasons include the use of private instead of business email addresses, surveying conflicting with competency management implementation, not having implemented competency management at all, and so forth. Furthermore, some weeks after the research was conducted the NVP decided to update the email addresses of the members of all divisions. It appeared that about 5\% of the 4000 available email addresses were invalid. Consequently, 5\% of the email addresses of the respondents in the current sample may have been invalid. Thus, we expect the use of nonexistent email addresses to have influenced the response rate as well.

The majority of the respondents were female (54\%). The respondents' age ranged between 25 and 60 years with most of the respondents in the category 36-40 years $(19 \%)$. All respondents completed higher vocational education (49\%) or university $(51 \%)$. The majority of the respondents were working in health care $(21 \%)$, government $(21 \%)$, or in commercial or financial service organizations $(21 \%)$ and the most were working in organizations with more than 200 employees $(70 \%)$. In total, 35\% of the respondents fulfilled a managerial position and 14\% had a temporary contract.

All respondents indicated that they used competency management in their daily work. A distinction was made between several competency management applications, namely individual development, performance appraisal and reward, recruitment and selection, or other applications. In total $91 \%$ of the respondents indicated that competency management was used for developmental purposes, 61\% indicated that competency management was used for performance appraisal and reward, and 58\% indicated that competency management was used for recruitment and selection. A total of $49 \%$ of the respondents mentioned other competency management applications. For example, some of the respondents indicated that competency management was used for strategic purposes, or to increase internal mobility or to instigate cultural change.

\section{Measures}

Attitude. Attitude toward competency management was measured using six items based on the theory of planned behavior. Examples of items are "I consider the use of competency management an opportunity for this organization" and "I am willing to use competency management". Responses were given on a five-point scale ranging from 1 (strongly disagree) to 5 (strongly agree). The alpha coefficient for this scale was .76.

Subjective norm. Subjective norm was measured using three items that were based on the theory of planned behavior. Examples of these items are "My colleagues have told me expressly that using competency management is desirable" and "My managers stimulate me to use competency management". Responses were given on a five-point scale ranging from 1 (strongly disagree) to 5 (strongly agree). The alpha coefficient for this scale was .57.

Perceived behavioral control. Perceived behavioral control was measured using two items based on the theory of planned behavior. These items are "I can easily adapt the competency model to my own demands" and "I have got sufficient knowledge to use competency management in daily tasks". Responses were given on a five-point scale ranging from 1 (strongly disagree) to 5 (strongly agree). The alpha coefficient for this scale was .63. 
Behavior. Behavior, or the use of competency management, was measured using six items based on the theory of planned behavior. Examples of items are "I have integrated the competency management in standard procedures" and "I apply competency management to daily routines in the area of performance appraisal". Responses were given on a five-point scale ranging from 1 (strongly disagree) to 5 (strongly agree). The alpha coefficient for this scale was .81 .

Commitment approach to competency management. Commitment approach was measured using nine items. These items were based on a questionnaire developed by De Caluwé and Vermaak (1999). Examples of items are "Employees were stimulated and inspired to use and accept competency management" and "During the design and implementation of competency management the emphasis was on creating employee motivation and employee commitment". Responses were given on a five-point scale ranging from 1 (strongly disagree) to 5 (strongly agree). The alpha coefficient for this scale was .83.

Control approach to competency management. Control approach was measured using six items. These items were based on a questionnaire developed by De Caluwé and Vermaak (1999). Examples of items are "The design and implementation of competency management was initiated by general management or by the board" and "During the design and implementation of competency management the emphasis was on controlling and directing". Responses were given on a five-point scale ranging from 1 (strongly disagree) to 5 (strongly agree). The alpha coefficient for this scale was .66.

\section{Analyses}

To examine the relationships between the variables we used correlation analysis. To investigate whether attitude, subjective norm, and perceived behavioral control explain variance in behavior we used regression analysis. Furthermore, to investigate whether attitude, subjective norm, and perceived behavioral control mediate the relation between commitment approach, control approach, and behavior we used the procedure as suggested by Baron and Kenny (1986). The significance of possible mediations was tested with the Sobel-test (Sobel, 1982).

\section{Results}

Table 1 presents the means, the standard deviations, and the correlations among the variables used in this study. First, we were interested in the relations between the commitment and control approaches and employees' attitudes, the subjective norm, and their perceived behavioral control. As can be seen in Table 1 and Table 2, correlations and betas of attitude and perceived behavioral control are higher for the commitment than for the control approach. Thus, we can conclude, in line with Hypothesis 1(a) and 1(c), that attitude and perceived behavioral control are more strongly related to the commitment approach than to the control approach. Subjective norm was correlated with the commitment approach as well as with the control approach. The beta weight of the relationship between the commitment approach and subjective norm was only marginally significant and, therefore, we had to reject Hypothesis 1(b). The beta-weight of the relationship between the control approach and subjective norm was nonsignificant. 
Table 1: Means, standard deviations, correlations, and reliabilities of the studied variables

\begin{tabular}{|c|c|c|c|c|c|c|c|c|}
\hline Variable & $M$ & $S D$ & 1 & 2 & 3 & 4 & 5 & 6 \\
\hline 1. Attitude & 4.05 & 0.48 & $(.76)$ & & & & & \\
\hline $\begin{array}{l}\text { 2. Subjective } \\
\text { norm }\end{array}$ & 3.50 & 0.70 & $.44^{\star \star}$ & $(.57)$ & & & & \\
\hline $\begin{array}{l}\text { 3. Perceived } \\
\text { behavioral control }\end{array}$ & 3.67 & 0.71 & $.60^{\star \star}$ & $.45^{\star *}$ & (.63) & & & \\
\hline 4. Behavior & 3.58 & 0.66 & $.46^{* *}$ & $.72^{\star *}$ & $.50^{* *}$ & $(.81)$ & & \\
\hline $\begin{array}{l}\text { 5. Commitment } \\
\text { approach }\end{array}$ & 3.60 & 0.60 & $.51^{* *}$ & $.41^{* *}$ & $.47^{* *}$ & $.48^{\star \star}$ & $(.83)$ & \\
\hline $\begin{array}{l}\text { 6. Control } \\
\text { approach }\end{array}$ & 3.13 & 0.63 & $.36^{\star}$ & $.39^{\star *}$ & .11 & $.45^{\star *}$ & $.50^{\star *}$ & (.66) \\
\hline
\end{tabular}

Note. Scale reliabilities (Cronbach's alphas) are in parentheses along the diagonal. Ns range from 41 and 43 due to incidental missing data.

${ }^{*} p<.05$, two-tailed ${ }^{* *} p<.01$, two-tailed

Table 2: Results of regression analysis for commitment and control explaining attitude, subjective norm, and perceived behavioral control

\begin{tabular}{|lccc|}
\hline Variable & Attitude & Subjective norm & $\begin{array}{c}\text { Perceived beha- } \\
\text { vioral control }\end{array}$ \\
\hline Commitment approach & $.44^{\star *}$ & $.28 \dagger$ & $.55^{\star \star}$ \\
Control approach & .14 & .25 & -.16 \\
\hline$R^{2}$ & .28 & .22 & .24 \\
Adjusted $R^{2}$ & .24 & .18 & .20 \\
$F\left(d f_{1}, d f_{2}\right)$ & $7.47(2,39)^{\star *}$ & $5.34(2,39)^{\star *}$ & $6.20(2,39)^{\star \star}$ \\
\hline
\end{tabular}

Note. Standardized regression coefficients are shown.

$\dagger p<.10^{*} p<.05^{* *} p<.01$, all tests are two-tailed

To test Hypothesis 2, we examined the correlations between attitude, subjective norm, perceived behavioral control, and behavior (see Table 1). Results showed that attitude, subjective norm, and perceived behavioral control correlate significantly with behavior in the expected direction, $r=.46, p<.01, r=72, p<.01$, and $r=.50, p<.01$ respectively. Thus, overall Hypothesis 2 is supported by the data. Especially, subjective norm has a large positive effect on the use of competency management. Thus, the opinion of one's colleagues appears to be an important determinant of the use of competency management.

Following the procedures as described by Baron and Kenny (1986), we examined Hypothesis 3 and 4 considering the mediating role of attitude, subjective norm, and perceived behavioral control on the relationship between the commitment and control approaches, and behavior (the use of competency management). According to the procedure proposed by Baron and Kenny, a variable functions as a mediator when the following conditions hold: (1) the independent variable (commitment/control) significantly affects the mediator (attitude, subjective norm, and perceived behavioral control), (2) the independent variable significantly affects the dependent variable 
(behavior), (3) the effect of the independent variable on the dependent variable is decreased in the presence of the mediator, and (4) the effect of the mediator on the dependent variable is significant. Perfect mediation holds if the independent variable has no effect when the mediator is controlled. We discuss the results for each of the expected mediators separately.

For attitude, the first condition of Baron and Kenny's (1986) procedure is met only with respect to the commitment approach. Therefore, Hypothesis 4(a), expecting attitude to mediate the relationship between the control approach and behavior, was not supported by our data. The commitment approach was significantly related to attitude, $\beta=.44, t=2.79, p<.01$ (Table 2). Table 3 shows that commitment was related to behavior, $\beta=.34, t=2.19, p<.05$ and, thus, the second condition of Baron and Kenny is met. Results showed that adding attitude to the regression equation decreased the relationship between commitment and behavior, $\beta=.22, t=1.33$, ns. The beta weight of attitude became, however, only marginally significant. Based on these results Hypothesis 3(a), expecting attitude to mediate the relationship between commitment and behavior, was not supported.

Table 3: Results of the mediation analysis explaining the use of competency management (behavior)

\begin{tabular}{|c|c|c|c|c|c|c|}
\hline & \multicolumn{6}{|c|}{ Behavior } \\
\hline Variable & Step 1 & Step 2 & Step 1 & Step 2 & Step 1 & Step 2 \\
\hline $\begin{array}{l}\text { Commitment } \\
\text { approach }\end{array}$ & $.34^{*}$ & .22 & $.34^{*}$ & .18 & $.34^{*}$ & .10 \\
\hline $\begin{array}{l}\text { Control } \\
\text { approach }\end{array}$ & $.28 \dagger$ & .24 & $.28 \dagger$ & .15 & $.28 \dagger$ & $.36^{* *}$ \\
\hline $\begin{array}{l}\text { Mediator: } \\
\text { Attitude }\end{array}$ & & $.28 \dagger$ & & & & \\
\hline $\begin{array}{l}\text { Mediator: } \\
\text { Subjective norm }\end{array}$ & & & & $.54^{\star *}$ & & \\
\hline $\begin{array}{l}\text { Mediator: } \\
\text { Perceived beh.control }\end{array}$ & & & & & & $.47^{\star \star}$ \\
\hline$R^{2}$ & $.29^{\star *}$ & $35^{* *}$ & $.29^{\star \star}$ & $.52^{\star *}$ & $.29^{\star *}$ & $.46^{* \star}$ \\
\hline$F_{R^{2}}\left(d f_{1}, d f_{2}\right)$ & $\begin{array}{c}7.85 \\
(2,38)^{\star *}\end{array}$ & $\begin{array}{l}6.62 \\
(3,37)^{\star *}\end{array}$ & $\begin{array}{l}7.85 \\
(2,38)^{* *}\end{array}$ & $\begin{array}{l}13.08 \\
(3,37)^{\star \star}\end{array}$ & $\begin{array}{l}7.85 \\
(2,38)^{* *}\end{array}$ & $\begin{array}{l}10.67 \\
(3,37)^{\star \star}\end{array}$ \\
\hline$\Delta R^{2}$ & & $.06 \dagger$ & & $.22^{\star *}$ & & $.17^{* *}$ \\
\hline$F_{\Delta R^{2}}\left(d f_{1}, d f_{2}\right)$ & $\begin{array}{l}7.85 \\
(2,38)^{\star *}\end{array}$ & $\begin{array}{c}3.23 \\
(1,37) \dagger\end{array}$ & $\begin{array}{c}7.85 \\
(2,38)^{\star \star}\end{array}$ & $\begin{array}{l}16.94 \\
(1,37)^{\star \star}\end{array}$ & $\begin{array}{c}7.85 \\
(2,38)^{\star \star}\end{array}$ & $\begin{array}{l}11.82 \\
(1,37)^{\star *}\end{array}$ \\
\hline
\end{tabular}

Note. Standardized regression coefficients are shown.

$\dagger p<.10^{*} p<.05^{* *} p<.01$, all tests are two-tailed

For subjective norm, the first condition of Baron and Kenny's (1986) procedure is not met. The commitment approach was only marginally related to subjective norm whereas the control approach was not at all related to subjective norm (see Table 2). However, the findings do point in the expected direction and therefore we continued our analysis. Adding subjective norm to the regression equation decreased the relationship between commitment approach and behavior, $\beta=.18, t=1.27$, ns, as well as the relationship between control approach and behavior, $\beta=.15, t=1.10$, ns. We found a significant relation between subjective norm and behavior, $\beta=.54, t=4.12$, 
$p<.01$. These results confirm the strong relation between the opinion of one's colleagues and the use of competency management (behavior), and are in line with Hypothesis 2(b). Even though the results point in the direction of mediation, due to marginal relationships, Hypothesis 3(b) and 4(b) were not supported. Thus, subjective norm did not mediate the relationship between commitment and behavior or the relationship between control and behavior.

For perceived behavioral control, the first and second condition of Baron and Kenny's (1986) procedure were met with respect to commitment approach. Commitment approach was significantly related to perceived behavioral control, $\beta=.55$, $t=3.43, p<.01$, and behavior, $\beta=.34, t=2.19, p<.05$ (Table 2). Adding perceived behavioral control to the regression equation caused a decrease in the relation between commitment approach and behavior, $\beta=.10, t=0.62$, ns, and an increase in the relation between control approach and behavior, $\beta=.36, t=2.55, p<.05$ (Table 3). The first effect holds that experiencing control over competency management decreases the effect of commitment approach on behavior. Thus, the third condition as proposed by Baron and Kenny is met. The beta weight of the relationship between perceived behavioral control and behavior was significant, $\beta=.47, t=3.44, p<.01$, and thus the fourth condition of Baron and Kenny was met as well. The Sobel-test (Sobel, 1982) showed significant results, $z=2.36, p<.05$ and, thus, perceived behavioral control was found to mediate the relation between commitment and behavior. Consequently, Hypothesis 3(c) is supported.

The second effect indicates a "suppressor effect" (MacKinnon et al. 2000; Shrout/Bolger 2002). A suppressor variable is defined as "a variable which increases the predictive validity of another variable (or set of variables) by its inclusion in a regression equation" (Conger, 1974: 36-37). Given the present data, adding perceived behavioral control to the regression equation strengthens the relation between control approach and behavior. Thus, for employees experiencing behavioral control over competency management a control approach has a larger positive effect on behavior than for employees experiencing less behavioral control over competency management. However, there was no significant relationship between control approach and perceived behavioral control, resulting in an unmet first condition of Baron and Kenny (1986). In conclusion, Hypothesis 4(c) was not supported by our data.

\section{Discussion}

The purpose of this study was to investigate the influence of commitment and control approaches on the actual use of competency management by human resource experts. First, we expected attitude, subjective norm, and perceived behavioral control to be more positively related to the commitment approach than to the control approach. Second, we expected attitude, subjective norm, and perceived behavioral control to mediate the relationship between the commitment and control approaches and the actual use of competency management.

In line with our expectations, the data showed that competency management implemented with a commitment approach brings about a more positive attitude towards the use of competency management than when implemented with a control approach. The commitment approach, by "winning hearts and minds" (Guest 1999, p.6), 
by eliciting organizational citizenship behaviors (Organ, 1988), and nonrole, unrewarded behaviors (Katz, 1964), may have led to a more positive attitude towards the use of competency management. In addition, we found a strong relation between commitment approach and perceived behavioral control. Behavioral control refers to being able to perform a certain behavior, as well as to "mastering" a certain behavior, and is compatible with Bandura's (1982) concept of perceived self-efficacy (Ajzen 1991). It seems likely that the commitment approach made human resource experts feel confident in their ability to use competency management in their daily work.

Furthermore, our data indicated that the opinion of one's colleagues (subjective norm) plays an equal role in both approaches. Thus, regardless of the approach towards competency management, the opinion of one's colleagues with respect to the use of competency management is always important to human resource experts. However, the effects are relatively small and replication within a larger sample is necessary to confirm the relationships. Additionally, correlation analysis pointed out that subjective norm was strongly related to behavior. This led us to conclude that the opinion of important others in the organization, irrespective of the approach chosen, is an important determinant of the use of competency management in daily work. The conclusion is in line with Van der Zee et al. (2002), who studied the use of structured interviews in personnel selection. In their study, subjective norm was an important predictor of the intention to use a structured interview as a selection method. Our findings suggest that for competency management to be used, it is important to create a positive social norm. Thus, for human resource experts to work with competency management, managers as well as colleagues have to support and stimulate the use of competency management. In some organizations, this may require a fundamental change in organizational climate.

Based on the procedures of Baron and Kenny (1986), we found perceived behavioral control to mediate the relationship between commitment approach and behavior. Thus, the data showed that part of the reason why the commitment approach leads to a greater use of competency management, is the fact that within a commitment approach employees experience more behavioral control. This finding has important practical implications. It implies that feelings of mastery over competency management and its applications may increase the use of competency management. This implication is in accordance with research on change-related topics that states that individuals are more likely to accept change whenever they have some determination (Deci et al. 1992), autonomy (Hackman/Oldham, 1976), control (Cherns, 1976), or perceived ownership (Clegg/Walsh 2004; Wall et al. 2002).

Besides important practical implications, the current study has several limitations that need to be taken into account. First, the rather low participation rate limits the generalizability of our findings. Non-respondents may, for example, have a different attitude towards competency management than respondents. However, we were able to check for selective participation by comparing some demographics of the sample and the population. No meaningful differences between the sample and the population were found with respect to sex, age, or education.

Second, our respondents hold a variety of different HR positions and represent different organizations and wide range of industries. Thus, we used a rather 
heterogeneous sample. On the one hand, this heterogeneity may have increased our generalizability. On the other hand, additional correlation analyses pointed out that some of the socio-demographical variables causing the heterogeneity in the current sample may have had some influence on the study outcomes. For example, the respondents' sex correlated significantly with attitude towards competency management indicating that women were more positive towards competency management than men, $r=.32, p<.05$. Managerial position and sector both correlated significantly with behavior or the use of competency management, respectively $r=-.31, p<.05$ and $r=.36, p<.05$. Thus, respondents with a managerial position used competency management more frequently than respondents not holding a managerial position and there appear to be differences between sectors with respect to the use of competency management.

In line with these findings we might conclude that the use of competency management depends on the context of a specific job, job area, or sector. The study's relatively small sample did not allow us to differentiate between job types or sectors. As a consequence, it is difficult to draw conclusions based on the results or on the results of the additional analyses. Future studies, among larger samples, should provide more insight in the effects of socio-demographical variables on the other variables used in this study.

Third, a comment should be made on the relatively low alpha of the scale for subjective norm. More findings may have been significant had the number of items in this scale and/or the sample size been larger. Fourth, we used self-report data and this may have caused common-method bias. However, in our instructions we assured confidentiality and asked respondents to fill out the questionnaire as accurately as possible. These actions may have minimized common-method bias. Nevertheless, such bias can never be ruled out completely.

A fifth limitation relates to the cross-sectional design. In line with Shippmann et al. (2000), we expected that a large percentage of the total sample would already be working with competency management. Due to the fact that measuring intentions in retrospect is impossible we decided to measure behavior instead resulting in a crosssectional design. Although, intentions have proven to be predictive of actual behavior (Van der Zee et al. 2002; Van Hooft et al. 2004, for a meta-analytic review see Armitage/Conner 2001) we do recognize the need for future research to investigate the mediating role of intentions in predicting the use of competency management, for example by using a longitudinal or a scenario design.

We argue for further research, not only within the same population, though using a larger sample, but also amongst other employees or amongst (line) managers. This creates further insights in the effects of commitment and control approaches on the use of competency management throughout the entire organization. Moreover, comparisons between employees, human resource experts, and line managers can be made with respect to, for example, their attitude towards and their use of competency management. Furthermore, we argue for qualitative research with in-depth interviews to learn more on the effects of the commitment and control approach on the use of competency management. 
In sum, the results of this study suggest that the opinion of important others on competency management, as well as the perceived behavioral control, may be important factors in increasing the use of competency management by human resource experts. Overall, the commitment and control approaches seemed to have different effects on attitude and perceived behavioral control, two determinants of behavior. We conclude that the use of competency management may be increased by creating empowerment, control and ownership. Within a commitment approach to competency management these characteristics are more salient than within a control approach. Thus, for competency management to become a human resource tool again instead of a human resource toy, we argue for increased perceived behavioral control through ownership, and for an organizational climate in which competency management is widely accepted.

\section{References}

Ajzen, I. (1985): From intentions to actions: A theory of planned behavior. In: J. Kuhl \& J. Beckmann (Eds.): Action control: From cognition to behavior (pp. 11-39): Berlin, Germany: Springer-Verlag.

Ajzen, I. (1991): The theory of planned behavior. In: Organizational Behavior and Human Decision Processes, 50: 179-211.

Ajzen, I./Fishbein, M. (1980): Understanding attitudes and predicting social behavior. Englewood Cliffs, NJ: Prentice Hall.

Armitage, J. C./Conner, M. (2001): Efficacy of the theory of planned behaviour: A meta-analytic review. In: The British Journal of Social Psychology, 40: 471-499.

Arthur, J. B. (1994): Effects of human resource systems on manufacturing performance and turnover. In: Academy of Management Journal, 37: 670-687.

Bach, S. (2000): From performance appraisal to performance management. In: S. Bach/K. Sisson (Eds.): Personnel management (3rd ed.): Oxford: Blackwell.

Bandura, A. (1982): Self-efficacy mechanism in human agency. In: American Psychologist, 37: 122-147.

Baron, R. M./Kenny, D. A. (1986): The moderator-mediator variable distinction in social psychological research: Conceptual, strategic, and statistical considerations. In: Journal of Personality and Social Psychology, 51: 1173-1182.

Becker, B. E./Huselid, M. A. (1999): Overview: Strategic human resource management in five leading firms. In: Human Resource Management, 38: 287-301.

Boselie, P./Paauwe, J./Den Hartog, D. N. (2004): Performance management en human resource management: Raakvlakken en perspectieven voor onderzoek [Performance management and human resource management: Common ground and research perspectives]. In: Gedrag/Organisatie, 17: 518531.

Boselie, P./Paauwe, J./Jansen, P. (2001): Human resource management and performance: lessons from the Netherlands. In: International Journal of Human resource Management, 12: 1107-1125.

Caska, B. A. (1998): The search for employment: Motivation to engage in a coping behavior. In: Journal of Applied Social Psychology, 28: 206-224.

Cherns, A. (1976): Principles of socio-technical design. In: Human Relations, 28: 783-792.

Clegg, C. W./Walsh, S. (2004): Change management: Time for a change! In: European Journal of Work and Organizational Psychology, 13: 217-239.

Conger, A. J. (1974): A revised definition for suppressor variables: A guide to their identification and interpretation. In: Psychological Measurement, 34: 35-46.

De Caluwé, L./Vermaak, H. (1999): Leren veranderen [Learning to change]. Alphen aan de Rijn: Samsom Uitgeverij.

Deci, E. L./Connell, J. P./Ryan, R. M. (1992): Self-determination in a work environment. In: V. H. Vroom/E. L. Deci (Eds.): Management and motivation. London: Penguin.

Fishbein, M./Ajzen, I. (1975): Belief, attitude, intention and behavior: An introduction to theory and research. Reading, MA: Addison-Wesley Publishing Company. 
Gelade, G. A./Ivery, M. (2003): The impact of human resource management and work climate on organizational performance. In: Personnel Psychology, 56: 383-404.

Giles, M./Cairns, E. (1995): Blood donation and Ajzen's theory of planned behavior: An examination of perceived behavioral control. In: The British Journal of Social Psychology, 34: 173-188.

Guest, D. E. (1999): Human resource management: The workers' verdict. In: Human Resource Management Journal, 9: 5-25.

Hackman, J. R./Oldham, G. R. (1976): Motivation through the design of work: Test of a theory. In: Organizational Behavior and Human Performance, 15: 250-279.

Heinsman, H./Koopman, P. L./Van Muijen, J. J. (2005): Competency management: A literature review. In: F. Avallone/H. K. Sinangil/A. Caetano (Eds.): Convivence in organizations and society (Vol. 12, pp. 39-46): Milan, Italy: Guerini Studio.

Huselid, M. A. (1995): The impact of human resource management practices on turnover, productivity, and corporate financial performance. In: Academy of management Journal, 38: 635-672.

Katz, D. (1964): Approaches to managing conflict. In: R. L. Kahn/E. Boulding (Eds.): Power and conflict in organizations (pp. 105-114): NY: Basic Books.

Koopman, P. L. (1991): Between control and commitment: Management and change as the art of balancing. In: Leadership and Organization Development Journal, 12: 3-7.

MacKinnon, D. P./Krull, J. L./Lockwood, C. M. (2000): Equivalence of mediation, confounding, and suppression effect. In: Prevention Science, 1: 173-181.

Organ, D. W. (1988): Organizational citizenship behavior: The good soldier syndrome. Lexington, MA: Lexington Books.

Parker, D./Manstead, A. S. R./Stradling, S. G./Reason, J. T./Baxter, J. S. (1992): Intention to commit driving violations: An application of the theory of planned behavior. In: Journal of Applied Psychology, 77: 94-101.

Paulsson, K./Ivergård, T./Hunt, B. (2005): Learning at work: Competence development or competencestress. In: Applied Ergonomics, 36: 135-144.

Prahalad, C. K./Hamel, G. (1990): The core competence of the corporation. In: Harvard Business Review, 68: 79-91.

Shippmann, J. S./Ash, R. A./Hesketh, B./Pearlman, K./Battista, M./Eyde, L. D. et al. (2000): The practice of competency modeling. In: Personnel Psychology, 53(3): 703-740.

Shrout, P. E./Bolger, N. (2002): Mediation in experimental and nonexperimental studies: New procedures and recommendations. In: Psychological methods, 7: 422-445.

Sobel, M. E. (1982): Asymptotic intervals for indirect effects in structural equations models. In: S. Leinhart (Ed.): Sociological methodology 1982 (pp. 290-312): San Fransisco: Jossey-Bass.

Storey, J. (1989): New perspectives in human resource management. London: Routledge.

Sugarman, B. (2001): A learning-based approach to organizational change: Some results and guidelines. In: Organizational Dynamics, 30: 62-76.

Truss, C./Gratton, L./Hope-Hailey, V./McGovern, P./Stiles, P. (1997): Soft and hard models of human resource management: A reappraisal. In: Journal of Management Studies, 34: 53-73.

Van der Zee, K. I./Bakker, A. B./Bakker, P. (2002): Why are structured interviews so rarely used in personnel selection. In: Journal of Applied Psychology, 87: 176-184.

Van Hooft, E. A. J. (2004): Job seeking as planned behavior: In search of group differences. Enschede, The Netherlands: Febodruk BV.

Van Hooft, E. A. J./Born, M. P./Taris, T. W./Van der Flier, H./Blonk, R. W. B. (2004): Predictors of job search behavior among employed and unemployed people. In: Personnel Psychology, 57, 25-59.

Wall, T. D./Cordery, J. L./Clegg, C. W. (2002): Empowerment, performance, and operational uncertainty: A theoretical integration. In: Applied Psychology: An International Review, 51: 146-169.

Walton, R. E. (1985): From control to commitment in the workplace. In: Harvard Business Review, 63: 77-84.

Wright, P. M./McMahan, G. C. (1992): Alternative theoretical perspectives on strategic human resource management. In: Journal of Management, 18: 295-320. 